\title{
Galeoos no sul do Brasil: alternativas na América
}

Regina Weber*

Resumo: Este artigo aborda algumas alternativas profissionais que se apresentaram aos imigrantes galegos no sul do Brasil, particularmente na capital do estado do Rio Grande do Sul, Porto Alegre, em meados do século passado. Muitos jovens emigraram da Galícia para a América nos anos 1950, seguindo correntes migratórias precedentes e alimentando novas migrações. Buscando alternativas para um mercado de trabalho restrito, onde a moeda e o consumo eram escassos, situação agravada em períodos de racionamento, muitos sonhavam com o enriquecimento fácil. Este não foi obtido; entretanto, outras possibilidades tornaram-se reais e estão aqui analisadas.

Palavras-chave: Imigração. Emigração. Galegos. Galícia. Brasil.

A imigração espanhola para o Brasil tem sido crescentemente estudada tanto por pesquisadores brasileiros quanto por estudiosos espanhóis. A maior parte dos estudos enfoca os casos de São Paulo e Rio de Janeiro, espelhando o peso da imigração nesses estados. ${ }^{1}$ Para o Rio Grande do Sul, o estado mais meridional do país, as publicações são praticamente inexistentes, o que motivou investigações sobre esse grupo.

* Professora do Departamento de História e Programa de Pós-Graduação em História da Universidade Federal do Rio Grande do Sul (UFRGS). E-mail: reginaw@terra.com.br. 
Uma das primeiras constatações da pesquisa "Espanhóis no sul do Brasil: imigração e etnicidade" apontou para a predominância de galegos entre os imigrantes espanhóis no sul do Brasil. ${ }^{2}$ Esse fato direcionou os rumos das investigações, das quais algumas conclusões estão aqui apresentadas.

Em meados do século XX, as repúblicas latino-americanas, Argentina, Venezuela e Brasil, eram os principais países de destino dos imigrantes espanhóis, quando, então, o fluxo imigratório espanhol passa a direcionar-se para as potências industrializadas da Europa Ocidental (FERNÁNDEZ VICENTE, 2005, p. 4). Entre a população imigrante no Brasil, os espanhóis são considerados o terceiro grupo em termos numéricos, superados apenas pelos portugueses e italianos. ${ }^{3}$

Definindo os galegos como "povo imigrante por excelência", González Martínez (2000, p. 242) recolhe dados que demonstram serem eles maioria entre os imigrantes espanhóis que vieram ao Brasil nas primeiras décadas do século XX. Para o Rio Grande do Sul, a população de espanhóis, nesse período, é estimada em 10 mil indivíduos, composta em sua maioria por galegos (GONZÁLEZ MARTÍNEZ, 2000, p. 250). Para meados do século XX, Elena Pájaro Peres (2003, p. 34-35) alinha dados numéricos expressivos que demonstram tanto a magnitude da imigração da imigração galega no conjunto da imigração espanhola (39\%) quanto o Brasil como o terceiro destino mais procurado pelos galegos (20\%), só perdendo para a Argentina (35\%) e Venezuela (30\%). No Brasil, a cidade de São Paulo, nesse período (1946-1964), é o destino principal desses imigrantes da Galícia que desembarcavam no porto de Santos (PERES, 2003, p. 233). ${ }^{4}$

Os censos demográficos mapeiam a multiplicidade de grupos de imigrantes no estado do Rio Grande do Sul. Para as décadas de 1940, 1950 e 1960, a presença de espanhóis no conjunto de estrangeiros revela-se pequena ( $3 \%$ a $5 \%$ ), se comparada a outros grupos, oscilando entre dois e três milhares de indivíduos (INSTITUTO BRASILEIRO DE GEOGRAFIA E ESTATÍSTICA, 1950, 1955, 1967). Italianos, uruguaios e alemães disputam as primeiras posições nessas décadas, seguidos por poloneses, russos e portugueses; os espanhóis são o oitavo grupo, após os argentinos..$^{5}$ Os espanhóis, assim como os nativos e os portugueses, foram os mais antigos 
ocupantes do território, quando os limites entre as Américas lusitana e hispânica ainda não estavam bem definidos; porém, com a imigração em massa de europeus no século XIX, destinados a lotes agrícolas no norte do estado, modificou-se o panorama demográfico regional, pela expressiva presença de italianos e alemães, seguidos dos poloneses. Essas correntes migratórias pregressas alimentariam novos fluxos migratórios no século seguinte. O número expressivo de uruguaios e argentinos justifica-se, em parte, por se tratarem de populações vizinhas. Os censos de 1920 a 1960 também mostram que os imigrantes espanhóis que chegaram ao Brasil dirigiram-se preferencialmente para o estado de São Paulo, em número sempre superior a 100 mil, e para o Rio de Janeiro, em número sempre acima de 10 mil indivíduos. Entretanto, não é a dimensão numérica que, necessariamente, determina a formação de comunidades de emigrados e a manutenção de laços entre os descendentes. Os imigrantes espanhóis no sul do Brasil identificaram-se tanto pela origem nacional quanto pela procedência regional.

Esta peculiaridade, de se distinguir o regionalismo dos imigrantes de um determinado país, não existe para todo e qualquer grupo que se estude. $\mathrm{O}$ país de recepção tende a homogeneizar o conjunto dos imigrantes pelos dados do passaporte e os habitantes da sociedade receptora também precisam de um reconhecimento mais abrangente dos adventícios, ou, como postula a teoria étnica, as exodefinições - o reconhecimento de um grupo social pela ótica de outros grupos - tendem a ser globalizantes (POUTIGNAT; STREIFF-FENART, 1988 , p. 144). Essa marca regional é um reflexo do forte regionalismo que sempre marcou a Espanha, desde sua constituição como um estado moderno. Ainda no século XVIII, quando a Espanha teria alcançado uma maturidade como conceito político e quando já haveria um pensamento espanhol com certas características comuns, suas estruturas econômico-sociais permaneciam muito variadas, sendo essa heterogeneidade descrita como "mosaico espanhol" por Dominguez Ortiz (1990, p. 119). Tal heterogeneidade transplantou-se para a América; em Cuba, ainda no período colonial, foram fundadas associações de "asturianos, canarios, andaluces, cántabros, vascos, casteláns, burgaleses, murcianos, aragoneses e baleares”, dentre as quais o Centro Galego da Habana era o mais importante (CARMEN 
BARCIA, 1999). A tendência a manter uma identidade específica mesmo em outro país certamente era maior para os emigrados das regiões espanholas reconhecidas por seu "nacionalismo histórico", que é o caso da Galícia, Catalunha e País Basco, cujos exilados constituíram organizações ou governos políticos no exílio (SIXIREI PAREDES, [s.d.], p. 175-176).

Contemporaneamente nós percebemos essas identidades regionais no cotidiano de associações. Um levantamento nos exemplares de 2007 do periódico La Región Internacional (1966-), que noticia as atividades e a situação dos emigrantes espanhóis em todo o mundo, evidencia que, nos países de destino, as comunidades de emigrantes organizam-se principalmente por suas regiões de origem (Centro Gallego de Buenos Aires, Unión Canaria de Venezuela, Residencia Asturiana de Ancianos, etc). Computando-se apenas as entidades existentes na América Latina, é inequívoca a predominância de associações de emigrantes galegos.

Essa "formalização das identidades étnicas" (SEYFERTH, 2000) em termos de uma identidade galega também é perceptível em Porto Alegre; todavia, as entidades principais, superando os marcos dos regionalismos, sempre foram aglutinadoras de todos espanhóis, unificando, portanto, uma comunidade que não era muito numerosa. A Sociedad Española de Socorros Mutuos de Porto Alegre foi fundada em 1893, seguindo um padrão de entidades mutualistas fundadas em outras cidades do Rio Grande do Sul. ${ }^{6}$ Em 1930 é criada a Casa de Galicia com a função de promover atividades culturais, dividindo tarefas com a Sociedade de Socorros Mútuos. É esta entidade que promove um ato cívico em 1931, comemorando a vitória dos republicanos na Espanha (KRELING, 1979, f. 50-54). Como em outros lugares, a comunidade espanhola local não ficou imune aos acontecimentos políticos na Espanha e, descontente com o republicanismo exacerbado dos membros da Socorros Mútuos, um grupo de imigrantes funda, em 1953, com o apoio do Consulado Espanhol, a Casa de España. ${ }^{7}$ Nessa entidade sempre ocorreram festividades que promoviam a memória das diferentes procedências regionais, com um destaque para práticas que remetem aos "galegos". No atual Centro Español, resultado da recente fusão das duas entidades em 1994, há uma 
placa, afixada em lugar de honra, que registra a "Homenage de la Casa de España a los gaiteiros gallegos [...] por su colaboración en la difusión de la cultura española”, datada de 15 de março de 1987. Há também um Departamento de Cultura Gallega ao qual são endereçadas algumas publicações atuais originárias da Espanha. E nas entrevistas tornou-se um senso comum, que efetivamente traduz uma realidade, a afirmação da predominância dos galegos entre os imigrantes.

Nossa pesquisa, cujo método central é a história oral, ${ }^{8}$ concentrou-se em emigrantes que saíram da Espanha entre o final da década de 1930 e 1960, ou seja, no segundo período da imigração espanhola para o Brasil (MACIEL; ANTONACCI, 1995, p. 192). Mesmo que a maior parte dos entrevistados tenha vindo na década de 1950, eles também nos trazem relatos de parentes que emigraram antes disso. Nesse intervalo de tempo está um dos eventos mais importantes da história contemporânea da Espanha, a Guerra Civil Espanhola, e é inevitável a referência dos entrevistados a esse acontecimento, que inclusive serve de baliza temporal para as narrativas. Contudo, a emigração enfocada, procedente da Galícia, não pode ser atribuída a fatores predominantemente políticos, ainda que encontremos muitos refugiados políticos na comunidade de espanhóis porto-alegrenses. ${ }^{9}$ Os fatores principais que determinaram a saída de jovens galegos da Espanha em meados do século XX são de ordem socioeconômica, como se expõe abaixo. Este estudo tende a corroborar o papel atribuído aos documentos pessoais, aí incluídas as "gravacións de memorias de vida narradas polos propios protagonistas”, por Soutelo Vásquez (1998, p. 101):

[...] ofrécennos outra perspectiva, individual e familiar, da influencia real que tiveron os famosos push-pull factors, do funcionamento concreto desas redes relacionais tecidas pola amizade, a confianza e a solidariedade étnica que coñecemos como cadeas migratorias, dos problemas da inserción sociolaboral e cultural no país de destino e tamén sobre o importantísimo papel desempeñado polos emigrantes retornados na mobilización sociopolítica das sociedades de partida. ${ }^{10}$ 


\section{Os povoados da Galícia e os automóveis dos retornados}

É inevitável associarmos a saída de pessoas da região da Galícia, em diferentes momentos históricos, com os relatos da existência de famílias numerosas, cujos filhos, ao atingirem a juventude, viam as perspectivas de trabalho, inclusive na terra, ficarem reduzidas. Ainda na década de 1950, a população rural da Galícia correspondia a 75\% da população total (PERES, 2003, p. 36). Um de nossos entrevistados mais idosos chegou ao Brasil em 1931. Ele veio para morar com uma irmã mais velha, que, por sua vez, viera porque o marido já estava aqui. E, precedendo seu cunhado, seu próprio pai já estivera no Brasil, antes mesmo do nosso entrevistado nascer: "Ela veio porque o marido já estava aqui, trabalhando. E meu pai já veio ao Brasil quatro vezes. Porque naquela época se costumava vir para as Américas. Porque o serviço lá era muito pouco, então eles vinham para as Américas arrumar um dinheirinho." Esse relato no remete a duas afirmações de Vazquez Gonzalez (1996, p. 314): (1) escapam aos dados estatísticos "la pluralidad de viajes de ida y vuelta al mismo o distinto destino"; (2) as cadeias pré-emigratórias funcionam como mecanismos retroalimentadores de processos migratórios. Tais fenômenos também podem ser analisados através do que Sayad (1998, p. 25) denominou "mecanismo de reprodução da emigração".

As lembranças desse senhor, ao contrário dos que vieram na década de 1950, não contêm referências ao período da Segunda Guerra Mundial, marcado pelo racionamento; a escassez à qual se refere é a de terras, quando da partilha entre os filhos numerosos, e do dinheiro:

É que antigamente as famílias tinham os filhos que Deus mandava. Hoje as pessoas têm os filhos que queiram; não o que Deus manda. Ali era diferente, tinha a família com dez, quinze, quatorze, dezesseis. Eu conheci uma família que tinha vinte, um senhor que tinha vinte filhos. Casou duas vezes e teve vinte filhos. Antigamente era isso. [...] porque na Europa, naquela época, todo mundo quase era muito econômico, 
porque o dinheiro era muito escasso. O dinheiro não circulava, porque trabalhava só o homem, e a mulher ficava em casa cuidando dos filhos. E o dinheirinho era "contadinho". [...] Eu me criei levando as vacas para os morros. [...] E tinha pastos também em lugares de base, mas aquele pedaço de base, normalmente, era tudo ocupado por famílias. Um tinha um pedacinho, tudo era diminuto e o dinheiro não circulava. E se numa família faleciam os principais, o resto ia dividindo o que tinha, porque não tinha mais dinheiro para comprar nada. Iam dividindo, dividindo e ficavam cada vez menores os pedaços de terra. (Emigrou em 1931, de Cervedo, província de Pontevedra).

É frequente entre os entrevistados a menção a uma busca de enriquecimento, explicitado como um desejo juvenil de ascensão social, particularmente de jovens do sexo masculino, que se entusiasmavam com a possibilidade de serem proprietários de um automóvel, tal como outros emigrantes que retornavam da América. Para compreendermos a força dessa imagem, é preciso que se resgate a paisagem dos povoados da Galícia em meados do século XX:

Desde pequeninha a gente ajudava, mãe, pai. Se não ia cavar na terra, que até ia também, mas cuidava dos bichos, do campo. Tinha vaca, tinha cabras, ovelhas, aquela coisa pra cuidar, tinha galinha... (Emigrou em 1956, de Santiago de Compostela).

Era tudo, vamos explicar: o camponês era um todo familiar e tinham algumas terras, assim separando tinha uma fazenda ou um sítio. A terra muito dividida em aldeias. Aldeias de doze, quinze, vinte casas. E as terras: tinha um pedaço de terra aqui, um pedaço de terra ali [...]. E viviam da cultura desses pedacinhos de terra e de gado. Todo mundo tinham suas vacas. Duas, três, quatro, cinco vacas. Os que tinham cinco vacas já podia se falar que eram pessoas bem de vida, uma família bem de vida. Mas no mínimo duas ou três vacas para leite, e uma parelha de bois, isso era 
sagrado também, porque era tudo feito na mão. Tudo o que se lavrava era na mão, e o boi era o que carregava o carro [...]. Todo o trabalho, arar a terra, tudo isso, na Galícia, era todo com arado puxado por boi. O boi arava, o boi levava o carro com os mantimentos. Tinham outras regiões da Galícia que no lugar usavam cavalos. [...] E cultivavam, sobretudo, milho, trigo, centeio. Tudo isso era, praticamente, para fazer pão. Cada uma dessas famílias, na casa tinha um forno também, porque eles mesmos que faziam o pão em casa. (Emigrou em 1952, de La Coruña).

Esse senhor da La Coruña nos traz uma preciosa descrição da vida camponesa das aldeias da Galícia. Famílias com posse de terra e animais domésticos. Por não serem contíguas, algumas posses familiares não podiam ser melhor aproveitadas, havendo resistências culturais a uma redistribuição que pudesse alienar terrenos que haviam pertencido à família e que, portanto, possuíam um valor afetivo, ou que eram considerados propícios ao cultivo de pasto. Uma vida de muito trabalho, que, no verão, dava lugar às festas dos povoados; e como eram muitos os povoados, os jovens se deslocavam a pé de uma festa a outra.

Normalmente eram dois dias, a festa era dois dias, neste lugar [casa dos avós]. [...]. Só que os do campo não iam somente às festas deles. Como eram lugares próximos assim, mais ou menos próximos [...]. Eu me lembro que num verão, eu fui para a casa de um primo, de um sobrinho de meu pai, mas ele era muito maior que eu. [...] Aquela época eu ia com ele. Praticamente eu ia a festas todos os dias. Acabava a festa daqui, no dia seguinte ou no fim de semana seguinte era a festa de lá [...]. Tinha uns lugares que eram longe pra caramba, mas a gente ia. E tudo andando, era todo o caminho andando. E eram moços e moças, todos andando, andando. Era no campo, não tinha estradas. (Emigrou em 1952, de La Coruña). 
É preciso relativizar as explicações dos próprios entrevistados que situam a motivação da emigração no fato de a Galícia ser uma região "pobre", pois, se efetivamente existem "refugiados econômicos", é questionável enquadrar como tais pequenos proprietários de terra com autossubsistência em produtos alimentícios, mesmo considerando a escassez das décadas de guerras (Guerra Civil e Segunda Guerra Mundial), período descrito por Fernández Vicente (2005, p. 4) como de "penúria econômica". E oportuno lembrar que a transição para o capitalismo, instaurando uma economia de mercado, fez com que os termos de troca se tornassem favoráveis aos homens da cidade (WALLERSTEIN, 1990, p. 123), convertendo o campo em periferia da cidade. Nesse contexto, as imagens de um mundo rústico e bucólico existem por contraste com regiões mais urbanizadas e industrializadas. Esse argumento guarda semelhanças com a leitura de Elena Pájaro Peres $(2003$, p. 165, 174) sobre o contexto da Espanha dos anos 1950 que incentivou o processo emigratório na Galícia: a abertura para uma sociedade de consumo, sob influência dos valores da cultura americana, tornou a penúria de dinheiro, sempre presente em sociedades de subsistência, mais difícil de ser suportada, particularmente para os jovens, mais vulneráveis aos apelos consumistas.

Estas análises permitem aproximações com a revisão historiográfica de Soutelo Vásquez (1998, p. 100), que constata uma superação da visão "pessimista" das migrações camponesas como uma reação a circunstâncias de mudanças globais por interpretações que indicam estratégias de mobilidade econômica e social ascendente. Sobre o papel dos retornados na mobilização pela ascensão, convém observar que "os casos de arrequecemento ou de ascensión social espectacular son, malia a súa visibilidade, escasos dentro do conxunto de retornados e emigrantes", mas é preciso considerar o efeito dos hábitos de consumo adquiridos em âmbitos urbanos latino-americanos sobre aqueles que ficaram, "pois fixeron máis visible o ascenso social e provocaron un contraste que actuou, pola súa vez, como poderoso factor de pulo para retroalimenta-la corrente emigratoria" (NÚÑEZ SEIXAS, 2001, p. 26). 
O desejo de busca do enriquecimento, muitas vezes encarnado em um símbolo da modernidade, o automóvel, ${ }^{11}$ está presente em várias narrativas dos entrevistados:

Todo mundo ia para Venezuela. Antes daquela parte, do meu pai, ir para Cuba... Também tinha Cuba e Argentina... Argentina e Uruguai. Eram os lugares onde os galegos, os espanhóis em geral, mas os que mais emigravam de Espanha eram os galegos. Porque os galegos eram também a província mais pobre da Espanha. Agora, quando eu era moço o lugar de migração era a Venezuela, era uma mina. Eu via aquele pessoal que saía da Espanha, das aldeias. No ano seguinte voltavam à Espanha num bruto de um carro, daqueles americanos. (Emigrou em 1952, de La Coruña).

Aí, um dia vi um espanhol que estava no Brasil. Voltou à Espanha para passear. E eu que naquele tempo era um menino $[. .$.$] Eu vi um emigrante bem arrumado e de carro.$ "Eu tenho que arrumar algo por aí também." (Emigrou em 1961 de Santa Comba, província de Santiago de Compostela).

Bom, eu acho que eu vim porque naqueles tempos se emigrava muito. Até porque... pós-guerra, bastante pobreza, digamos assim. A gente só ouvia falar naqueles que viajavam. A América, ganhar dinheiro, enriquecer; o sonho. (Emigrou em 1956, de Santiago de Compostela).

Quando contraposta às imagens dos que voltaram da América, transitando de automóvel onde o habitual era se deslocar a pé, a Galícia de uma Espanha do pós-guerra, com racionamento de mercadorias de consumo, parecia "pobre", mas na descrição dos primeiros tempos no outro lado do Atlântico, não se realizando o sonho do enriquecimento fácil, a memória é reenquadrada e a terra natal é relembrada de outro modo. A última narrativa acima é de uma senhora, que contrapõe o sonho ao arrependimento: " $\mathrm{Na}$ verdade, de início a gente se arrepende mil vezes, mas... depois se 
acostuma." Seu esposo, um riojano, lembra dos inúmeros imigrantes espanhóis que foram "repatriados", isto é, que não possuíam recursos para arcar com o próprio retorno. ${ }^{12} \mathrm{O}$ emigrante de La Coruña encontrou em São Paulo outros espanhóis que moravam numa pensão "pior do que viviam na Espanha", comparando o local a um cortiço. Ele empregou-se depois, como desenhista numa fábrica de vagões de trem de Belo Horizonte, capital do estado de Minas Gerais, para onde se mudou. Dali aventurou-se no estado de Goiás, ainda em busca do enriquecimento rápido através do garimpo de diamantes. $\mathrm{Na}$ viagem de trem para o centro-oeste brasileiro, o gado bovino é que sugere a imagem da fartura da Galícia: "Eu me assustava com o gado que eu via no campo. Eu estava acostumado a ver aqueles enormes bois e vacas de leite. $\mathrm{E}$ via no campo as vacas, quando a gente passava; parecia só o esqueleto, magrinhas, magrinhas."

A fortuna fácil não foi obtida, mas o Brasil ofereceu outras alternativas para os que tiveram recursos, paciência ou simplesmente sorte.

\section{A América e suas alternativas}

Tanto Elena Pájaro Peres, pesquisando a migração galega em São Paulo em meados do século XX, quanto Alejandro Vazquez Gonzalez, analisando a imigração galega ao rio da Prata entre 1830 e 1930, apontam algumas limitações dos registros sobre as profissões dos emigrantes que constam nos documentos. No período em que as autoridades brasileiras passaram a exigir a comprovação de uma profissão considerada útil para conceder visto, o registro no passaporte poderia ser falsificado (PERES, 2003, p. 233). Referindo-se ao final do século XIX, Vazquez Gonzalez (1996, p. 330-331) questiona se a atividade declarada referia-se à exercida na Galícia ou a que os imigrantes iriam dedicar-se na América, e também destaca a diversidade dos ofícios rurais e urbanos declarados.

Os registros de sócios da Casa de España de Porto Alegre, existentes a partir de 1950, constituem-se de fichas que reuniam todos os membros da família num mesmo vínculo. Das 89 fichas 
localizadas, com o campo da profissão ora registrado para todos os membros da família, ora para nenhum, um pouco menos de $60 \%$ (53 fichas) são de nascidos na Espanha. ${ }^{13}$ Dessas fichas de estrangeiros, obtivemos as profissões registradas na tabela abaixo com suas respectivas porcentagens, que tendem a apontar um predomínio de profissionais de classe média urbanizada, com ausência de trabalhadores agrícolas e pequeno número de operários. Podemos considerar que houvesse uma diferença entre os associados da Casa de España e os da Sociedad de Socorros Mutuos, com esta última agregando espanhóis de perfil mais modesto, conforme supõem alguns entrevistados. Contudo, o mais provável é que estamos diante de registros dúbios, que mais encobrem que elucidam, particularmente em categorias genéricas, como "comerciante" e "industrial". Nesta última categoria, por exemplo, está registrado um associado nascido em Valladolid em 1953, solteiro, cuja inscrição foi feita a julgar por uma anotação na ficha - em 1974, quando ele teria 21 anos, o que nos induz à suposição que "industrial" pode também ser "industriário" ou talvez artífice.

\section{Tabela 1 - Profissões dos associados à Casa de España}

\begin{tabular}{ccc}
\hline Profissão registrada ${ }^{14}$ & $\begin{array}{c}\text { Número de } \\
\text { registros }\end{array}$ & Porcentagem \\
\hline Comerciante & 15 & 28,0 \\
\hline Industrial & 10 & 19,0 \\
\hline Aposentado & 4 & 7,5 \\
\hline Comércio & 4 & 7,5 \\
\hline Metalúrgico & 3 & 5,6 \\
\hline Economista & 3 & 5,6 \\
\hline Engenheiro & 3 & 5,6 \\
\hline Outros & 10 & 19,0 \\
\hline
\end{tabular}

Fonte: CASA DE ESPAÑA. Hoja Cadastral. Porto Alegre. 1950-1960.

Nessas zonas em que os documentos escritos mostram-se opacos, as fontes orais trazem alguma clareza. As histórias de vida 
desses imigrantes espanhóis de meados do século XX são bastante diversificadas. Inicialmente é preciso distinguir aqueles que vieram já direcionados para alguma atividade específica, e que, em virtude de seus conhecimentos técnicos especializados, obtiveram boas colocações no mercado de trabalho, daqueles que, mesmo tendo habilidades em algum ofício além das lides rurais, buscaram outras alternativas. Esse segundo grupo, que é a maioria, de modo geral, passou da condição de assalariamento para a busca de posições autônomas.

Para exemplificar a primeira situação, descrevemos uma família, originária da cidade portuária de Vigo, que trouxe contribuições técnicas a dois diferentes ramos de produção no sul do Brasil: a fabricação de vitrais artísticos e a construção de embarcações de pesca. Quem nos informa dos fatos foi um senhor que emigrou aos cinco anos de idade, em 1947, cujo pai dominava a fluorografia, arte de gravação em vidro por processo químico, e participou da confecção de vitrais em igrejas, residências e prédios, tanto na capital como em outras cidades do Rio Grande do Sul. Sua família, na verdade, não partiu de Vigo, mas da cidade portuguesa de Porto, para onde seu pai fora trabalhar e de onde não retornara para servir no exército franquista. Nesses mesmos anos em que temia ser preso se retornasse à Espanha, o pai de nosso narrador recebeu um convite do proprietário da mais importante casa de vitrais do sul do país.

$\mathrm{Na}$ decisão de transferência da família para o Brasil teve importância, além do convite do empresário, o fato de que havia um tio materno já instalado na cidade. Esse tio, seus irmãos e o pai deles, avô de nosso informante, pertenciam a uma importante família de construtores de embarcações navais. Por seus conhecimentos, o avô fora convidado a participar na construção de um estaleiro no Brasil. Na década de 1930, instalado na cidade de Itajaí, no estado de Santa Catarina, esse avô e dois de seus filhos homens acompanhavam o processo de fabricação das embarcações desde o corte da madeira nas matas próximas. Tal como os atuais técnicos especializados que dão assessorias em outros países, esses espanhóis iam e vinham entre Brasil e Espanha. Entretanto um deles ficou no Brasil, casando-se aqui e se estabelecendo em Porto Alegre, que também é uma cidade portuária, ali se dedicando à 
construção de embarcações. Esse tio materno de nosso entrevistado foi quem influenciou, além do proprietário da fábrica de vitrais, a vinda de seus pais para o Brasil. Alguns anos depois, mais dois tios paternos vêm para o Brasil. Duas embarcações de pesca em alto-mar haviam sido construídas para uma empresa de pesca da cidade de Rio Grande pelo armador de Vigo, mas seus novos proprietários não estavam obtendo sucesso na captura de peixes. Tendo sido constatado que o problema estava não nas embarcações mas na perícia dos pescadores, o tio de nosso informante sugeriu chamar da Espanha mais dois membros da família para capitanearem os barcos, que chegaram ao final da década de 1940.

Portanto, se acompanharmos a narrativa acima, vemos que espanhóis da cidade de Vigo tiveram influência, desde a década de 1930, nas atividades náutica e pesqueira das três maiores cidades portuárias do sul do Brasil: Itajaí, Porto Alegre e Rio Grande, atuando ora como empresários, ora como administradores de importantes empresas do ramo. E também no ramo artístico-artesanal da fluorografia.

Antes de examinar casos do segundo grupo, dos que foram alterando suas posições no mercado de trabalho do país de acolhida, é oportuno esclarecer uma questão. Se a maior parte da população que emigra provém de áreas rurais, sua alocação principal não seriam os setores agrícolas do Brasil? E ainda, se a partir da década de 1950 o governo brasileiro passa a priorizar imigrantes com qualificações, como ainda predominam os jovens de povoados rurais galegos entre os imigrantes espanhóis? Uma primeira resposta às perguntas é considerar uma limitação da pesquisa: estudos sobre grupos étnicos dependem de manifestações destes, tais como entidades associativas, jornais, escolas, que, via de regra, são mais frequentes em espaços urbanos. Mesmo com essa limitação, temos notícia de espanhóis que eram agricultores no Rio Grande do Sul. "Aqui pro Brasil, pra ir pra capital tinha que ter uma profissão. Se não fosse numa profissão tinha que ir direto pro campo", nos explica um senhor. "Se tu venías para agricultura, pelo menos cuatro años tenía de estar na agricultura", afirma outro, justificando a relutância da Delegacia de Estrangeiros em conceder a "carteira modelo 19", documento burocrático brasileiro que habilitava estrangeiros ao 
trabalho na cidade. Se tal documento era ambicionado, a emigração galega do século XX mantém semelhanças com a do século precedente, pois, segundo Vazquez Gonzalez (1996, p. 343) "los gallegos emigraron primordialmente desde um ámbito rural em Galicia, a um medio fundamentalmente urbano em América".

Todavia, um outro fator precisa ser considerado: mesmo aqueles egressos de povoados rurais e conhecedores das atividades agrícolas e das lides com animais domésticos podiam dominar algum outro ofício, como o de pedreiro (albañil) ou cantaria. ${ }^{15}$ Outras narrativas mostram que uma família poderia ter seu lar no campo, mas algum de seus membros, particularmente o pai, poderia dedicar-se a outras atividades, como comércio ou construção, inclusive deslocando-se a outro país. Por exemplo, nosso entrevistado de Pontevedra identificou-se como sendo "de origem de agricultura" e depois, ao contar que o pai já viera ao Brasil quatro vezes "arrumar um dinheirinho", explica: "O meu pai, porque era uma pessoa que tinha uma profissão: era um canteiro especializado." Uma senhora que chegou ao Brasil em 1961, originária de Cavardino, na província de Ourense, descreve a vida comunitária na "finca" dos pais: "Hoje era no terreno dos meus pais, daí ia aquele monte de gente; amanhã era no terreno de outra pessoa. Se ajudavam uns aos outros." Quando indagamos se, através do cultivo e da criação dos animais, eles obtinham renda para adquirir produtos como móveis e roupas, ela esclarece que o pai também trabalhava na estrada de ferro. Esses dados pontuais permitem um diálogo com o panorama mundial do pós-Segunda Guerra Mundial descrito por Klein (2000, p. 27): as migrações europeias transatlânticas levam para a América trabalhadores qualificados e profissionais nesse período.

A "profissão", portanto, funcionava como uma espécie de passaporte para a entrada no Brasil, garantindo a circulação pelo mundo urbano. Mas, depois de desembarcados, os jovens imigrantes estavam livres para se dedicar a quaisquer alternativas. Um emigrante de um povoado próximo à cidade de Vigo trabalhara tanto no campo, com a família ou colhendo uva para proprietários maiores na época da vindima, quanto como pedreiro e com ferro, o que lhe permitira arrumar trabalhos temporários, inclusive em outras províncias da Espanha. Foi como albañil que ele veio ao Brasil em 1954. 
Em Porto Alegre foi trabalhar como garçom num bar cujo proprietário era um espanhol da Galícia. Só depois de dois anos nessa atividade é que voltou a trabalhar em construção. Outro entrevistado, originário de Santa Comba, um povoado com 70 habitantes, nos informou que "trabalhava na terra e também trabalhava na pedra" e que, para emigrar, declarou que era "marceneiro", pois também teria conhecimentos nesse ramo. ${ }^{16}$ Porém, quando desembarcou no Rio de Janeiro, em 1961, não se dedicou a nenhuma das duas profissões, empregando-se sem dificuldade em um restaurante, pois "naquela época tinha trabalho demais". Quando veio ao Rio Grande do Sul, em 1964, também trabalhou em restaurante. Indagado se não voltou a trabalhar com entalhe em pedra, ele nos respondeu:

Era muita poeira. Era um trabalho muito solitário, exigia muita paciência, eu não tenho muita paciência. É um trabalho muito solitário, uma peça inteira e qualquer coisa o trabalho vai por água abaixo, tem que ter uma paciência muito grande. (Emigrou em 1961, da província de Santiago de Compostela).

As levas de emigrantes alemães, italianos e poloneses, originárias de áreas rurais da Europa, que ocuparam o sul do Brasil no século XIX, foram distribuídas em lotes de terra e deram origem a um campesinato. No século XX, num Rio Grande do Sul com expressivo desenvolvimento urbano e com suas áreas rurais bastante povoadas, os imigrantes buscam principalmente as cidades. Filhos de pequenos proprietários rurais, os jovens galegos, alimentados pelo sonho de enriquecimento, não almejavam tornar-se assalariados rurais em outro país. Eram outras suas ambições:

Os que decidiam pela emigração eram quase sempre aqueles que se recusavam a perpetuar o círculo das opções oferecidas tradicionalmente ao camponês galego: o trabalho na lavoura de subsistência; o confinamento em ofícios artesanais enquanto carpinteiros, marceneiros, canteiros etc; a proletarização iminente nas grandes cidades espanholas; o submetimento à disciplina militar. Esse círculo era sistematicamente rompido pela emigração, que trazia em si a promessa da acumulação 
pecuniária, que possibilitaria novas oportunidades no futuro, com a aquisição de novas terras ou a montagem de um negócio próprio. (PERES, 2003, p. 191).

Quando se pesquisam grupos imigrantes e seus descendentes, sempre corremos o risco de referendar ideologias de ascensão social. Se jovens emigram de uma área de pequenos proprietários rurais para um país em processo de urbanização e desenvolvimento, com um elástico mercado de trabalho, existem muitas chances de se tornarem adultos com algum poder aquisitivo. A condição de emigrante que tomou a decisão de partir, somada à condição de estrangeiro, motivam o indivíduo a agir e a obter reconhecimento. Tais comportamentos, por sua vez, costumam gerar uma ideologia do trabalho, que cada grupo imigrante supõe ser o único a possuir. ${ }^{17}$ $\mathrm{O}$ pesquisador do tema ainda enfrenta um outro fator que pode conduzi-lo a referendar uma ideia de "sucesso": é sempre mais difícil obter dados sobre os menos favorecidos de qualquer grupo social. Nesta pesquisa, pouco sabemos sobre os que retornaram porque estavam em situações difíceis aqui no Brasil e, dentre os aqui residentes, as diretorias das entidades tendem a indicar para entrevista os mais bem-sucedidos. ${ }^{18}$ Mesmo considerando tais limitações, os dados desta pesquisa nos permitem afirmar que muitos galegos que emigraram em meados do século XX para o sul do Brasil lograram, em um maior ou menor lapso de tempo, fazer parte de estratos médios da sociedade local. Não retornaram a Galícia alguns anos depois para circular entre os povoados com automóveis, tais como as imagens gravadas em sua juventude, mas também não retornaram sem nada nas mãos. Quando voltaram, depois de uns vinte anos, não o fizeram para exibir os bens adquiridos - entre estes, efetivamente um automóvel -, mas para rever a terra natal e os parentes.

Um estudo qualitativo não habilita muitas demonstrações numéricas, mas possibilita algumas aproximações. O que se deduz das entrevistas é que, assegurada a sobrevivência, os entrevistados buscaram trabalhos que lhes garantissem autonomia. ${ }^{19}$ Quando há uma estrutura familiar já instalada no novo país, a mudança é mais 
rápida. O jovem de Pontevedra, que chegou ao Brasil em 1931, veio para ajudar seu cunhado que trabalhava com açougue, ramo ao qual esse parente dedicou-se depois de trabalhar com cantaria. Posteriormente trabalhou um tempo como assalariado e estabeleceuse, ele próprio, com um açougue. $\mathrm{Na}$ sua narrativa, a escassez de dinheiro na Europa teria sido um fator de estímulo à acumulação no Brasil:

E eu fui me empregar, andei empregado. E depois comprei um açougue, naquela época era a única coisa que eu sabia fazer. Bem na Cristóvão Colombo. Trabalhava como um desesperado, levantava três, quatro horas da manhã, e ficava o dia inteiro. E foi, juntei um dinheirinho. Muito econômico porque na Europa, naquela época, todo mundo quase era muito econômico, porque o dinheiro era muito escasso. (Emigrou em 1931, de Cervedo, província de Pontevedra).

Em 1948, quando nosso narrador estava com 32 anos, ele comprou seu primeiro carro. Alguns anos depois, a família, que passara da cantaria para o comércio de carnes, tem condições de passar a outro ramo: em 1954, o entrevistado e dois dos filhos de sua irmã adquiriram um cinema, que se tornou sua atividade durante os próximos 26 anos. Nesse mesmo ano de 1954, chegou a Porto Alegre o espanhol de Ourense que, depois de uns dez anos, após ter trabalhado como assalariado em bar e em construção civil, decidiu que não queria mais trabalhar assim. Arrumou uma máquina de afiar e passou a trabalhar na rua. "Era um trabalho mais livre, sem patrão. Ganhava pouco, mas era mais livre.” Após um tempo, conseguiu um ponto fixo para seu negócio de afiação no centro da cidade. Mesmo com possibilidades e trajetórias diferentes, os dois entrevistados tiveram filhos universitários e ambos visitaram a Espanha, o primeiro após 25 anos da partida e o segundo após 20 anos.

Duas outras trajetórias permitem avaliar tanto a diversidade dos emigrantes da Galícia quanto as alternativas abertas no Novo Mundo. Acompanhar trajetórias femininas é mais difícil, pois muitas vezes a vida profissional das mulheres termina com o casamento, quando elas passam a garantir o funcionamento doméstico indispen- 
sável ao trabalho do marido. A senhora que emigrou de Santiago de Compostela em 1956 era filha de uma relação extraconjugal de um homem "rico", que herdara muitas terras, mas que nunca soube administrar seu patrimônio. Após transferir-se com sua família para o Brasil, ele buscou a filha natural, então com 12 anos, para ajudar a cuidar dos irmãos menores. Depois ela foi trabalhar como empregada doméstica na casa do vice-cônsul, e chamou sua mãe da Espanha. Aos 20 anos casou-se com um espanhol 13 anos mais velho, emigrado da província de La Rioja, que, como técnico agrícola, já obtivera bons rendimentos em plantações, tanto no interior do estado de São Paulo quanto no Rio Grande do Sul. Recém-casados, o casal transfere-se para Uruguaiana, na fronteira do Brasil com a Argentina. Depois de sete anos, retornam a Porto Alegre e tornamse ecônomos de sociedades espanholas. O que chama atenção nessa biografia são os destinos diferenciados do pai, que nasceu rico mas morreu pobre, vivendo com o auxílio que o governo espanhol concede aos emigrantes, e da filha, que atualmente tem um bemsucedido empreendimento de tele-entrega de paellas. ${ }^{20}$ As conquistas dessa senhora não podem ser atribuídas ao casamento com um homem de posses, pois este desperdiçou parte de seus ganhos quando era solteiro e as atividades do casal nas últimas décadas devem-se aos conhecimentos culinários da esposa.

Um senhor que se aposentou trabalhando em uma empresa de seguros de indústrias de grande porte, sediada em São Paulo e com filial em Porto Alegre, nos traz um relato dos riscos a que a busca pelo enriquecimento podia expor jovens emigrados. Esse emigrante de La Coruña tem vívidas memórias dos campos galegos, onde nasceu e viveu seus primeiros anos de vida e onde permaneceram seus avós. Seu pai, que havia acumulado algum dinheiro após sucessivas viagens a Cuba, instalou um mercado na estrada. Depois a familia transferiu-se para a cidade, onde seu pai dedicou-se à construção de prédios para alugá-los. Sua decisão de emigrar para a América deve-se ao fato de estar enamorado de uma moça cuja família não o considerava um bom pretendente. Era início da década de 1950 e estava difícil conseguir emprego. Ele pretendia ir para a Venezuela, que, nessa época, era "o melhor lugar para ganhar dinheiro", mas como lá "já não estavam aceitando mais gente", 
veio para o Brasil. Como vimos, seus conhecimentos de construção o motivaram a candidatar-se a uma vaga - anunciada em jornal - de desenhista numa empresa de vagões de trem de Belo Horizonte. Nessa cidade ele encontra três espanhóis da Catalunha e também revive o sonho de enriquecimento fácil:

Em Belo Horizonte eu ouvia muito falar de Diamantina. De que lá para Goiás havia um garimpo. Só se falava nisso. Toda aquela turma só falava em garimpo: "Não, porque eu fui para garimpo, porque lá em Goiás se ficava rico em pouco tempo." E minha cabeça começou a andar meio louca, então eu disse: "Vamos para lá." E fui. Fui com um desses rapazes espanhóis, eram catalães os três [...]. Fomos para Goiás, de trem. (Emigrou em 1952, de La Coruña).

Em Goiânia, capital do estado de Goiás, no centro-oeste brasileiro, esses dois rapazes - um galego e outro catalão - encontram dois outros espanhóis; um deles, que também era galego, aceita juntar-se ao grupo e os três jovens vão para as jazidas fluviais do rio Araguaia. Acostumado a nadar, esse emigrante da La Coruña tinha facilidade de mergulhar em busca de diamantes, mas nunca os encontrou. Os três companheiros acabaram por se separar. O outro galego, que se recusava a andar vestido, depois de muito ser picado por mosquitos, teve que ser levado a um hospital em Goiânia, quando já estava delirando. O catalão escreveu aos conterrâneos que estavam em Belo Horizonte e estes enviaram dinheiro para ele poder retornar. Nosso narrador seguiu um rumo que lembra uma cena de road movie. Adentrou num mato e depois de cinco dias saiu numa estrada. Encontrou um padre espanhol em missão religiosa e este o aconselha a sair da região. Começa então sua trajetória de retorno do oeste ao leste brasileiro. Em uma pensão na cidade de São Paulo, onde almoçavam e se hospedavam outros espanhóis, um funcionário com cargo de chefia em uma firma de corretagem de seguros lhe sugeriu que tentasse uma vaga na empresa, por sua habilidade com desenho. "E a empresa gostava de espanhóis, achavam que espanhóis eram bons.” Ali, mais tarde, ele tornou-se técnico em divisão de riscos, orientando grandes indústrias no 
Rio Grande do Sul e outros lugares a minimizar riscos. Essa narrativa das peripécias de jovens que vivenciaram uma saga de busca de tesouros nos alerta para o fato que sabemos dos acontecimentos pelos sobreviventes e nem sempre podemos contabilizar os que adoeceram gravemente ou os que morreram.

É importante distinguir sociologicamente entre imigrantes que chegaram já inseridos em uma estrutura familiar, que norteou os seus passos iniciais, e os jovens que puderam aventurar-se justamente por não estarem muito envolvidos em uma ordem social e nem possuírem "interesses adquiridos de ordem econômica ou espiritual” (MANNHEIM, 1980, p. 53). Nesses dois conjuntos de imigrantes galegos - os grupos familiares e os jovens independentes - são observáveis dois pontos em comum: (a) uma versatilidade profissional, caracterizada pela ocupação de novas posições no mercado de trabalho, quando as oportunidades assim o permitissem; (b) o papel importante que tiveram outros espanhóis - galegos ou não - seja como companhia de aventuras em busca de riquezas, seja em uma inserção profissional mais estável, mais vantajosa, ou simplesmente mais "familiar", no sentido de "comunidades de descendência e cultura" (FENTON, 2003, p. 13). Este segundo fator remete a considerações das modernas teorias da etnicidade que apontam o peso da etnicidade entre grupos movidos por interesses econômicos (GANS, 1996; GLAZER, MOYNIHAN, 1975) e vem ao encontro de estudos que demonstram que o "capital relacional" facilita a integração socioprofissional do imigrante na sociedade receptora (SOUTELO VÁSQUEZ, 1998, p. 103).

Mesmo considerando que pouco sabemos dos "repatriados" ou dos que empobreceram ou adoeceram ainda jovens, ou, por outro lado, dos imigrantes espanhóis cuja fortuna e modo de vida mais privado os torna pouco visíveis, pode-se dizer que os emigrantes que saíram da Galícia para o sul do Brasil certamente não retornaram em poucos anos a bordo de carros que se destacariam na paisagem bucólica dos povoados rurais, tal como a imagem guardada em sua memória. Contudo, aqui não apenas não passaram por nenhum tipo de racionamento, como também conseguiram ter mais "dinheirinho" nas mãos. Para outros, mesmo que não tenham sido militantes políticos, não estar submetido às contingências de um 
regime militar também foi importante. Em suma, para os que se tornaram jovens numa Europa que emergia de guerras internas, a América, mais uma vez, cumpriu o papel de ser o futuro.

\section{Galicians in the South of Brazil: alternatives in America}

Abstract: This article broaches some professional alternatives presented to Galician immigrants in the South of Brazil, especially in Rio Grande do Sul state's capital, Porto Alegre, in mid- $20^{\text {th }}$ century. Many young-men emigrated from Galicia to America in the 1950s, following preceding migratory currents and nurturing new ones. Searching for alternatives in a restrict labor market, where money and consumption were scarce, an aggravated circumstance in rationing periods, many of them dreamed about easy enrichment. However, as it was not achieved, other possibilities became real and they are here analysed.

Keywords: Immigration. Emigration. Galicians. Galicia. Brazil.

\section{Notas}

${ }^{1}$ Sobre a imigração espanhola para o estado de São Paulo podemos citar os estudos de Oliveira (1997), Maciel e Antonacci (1995), Soutelo Vázquez (1998), Peres (2003) e Cánovas (2004); para o caso do Rio de Janeiro ver Muniz (1996); Guimarães (1997) e Silva (2006). A obra de Klein (1994), também bastante centrada em São Paulo, faz um extenso levantamento de censos e outros dados quantitativos.

${ }^{2}$ A pesquisa contou com bolsas da Fundação de Amparo à Pesquisa do Estado do Rio Grande do Sul (Fapergs) e do CNPq (Propesq/UFRGS). A autora deste artigo é imensamente grata a Evaristo Gallego Iglesias pelas suas valiosas contribuições à pesquisa.

${ }^{3}$ De acordo com os dados do Instituto Brasileiro de Geografia e Estatística, no período de 1934 a 1963 - décadas abrangidas por esta pesquisa -, as imigrações espanhola e italiana para o Brasil tem magnitude bastante semelhante (126 mil). Os portugueses, em número bem maior, totalizam 403 mil (ALMANAQUE ABRIL 1979, 1978).

${ }^{4}$ Tomando por parâmetro nossos entrevistados, Santos era o principal porto de desembarque mesmo para aqueles que se dirigiram a outros estados do país. Outro porto de desembarque citado é o Rio de Janeiro.

${ }^{5}$ A nacionalidade nem sempre coincide com o pertencimento étnico. Entre os portadores de passaporte russo, há muitos imigrantes que são etnicamente poloneses ou alemães; assim como muitos russos, poloneses e alemães são judeus. 
${ }^{6}$ As primeiras associações mutualistas de espanhóis foram fundadas em cidades de fronteira do Brasil com Uruguai e Argentina: em Bagé (1868), Livramento (1879) e Uruguaiana (1876) (KRELING, 1979, f. 29-40).

${ }^{7}$ Também no Uruguai as lideranças dos imigrantes espanhóis dividiram-se ideologicamente (ver Zubillaga, 2000).

${ }^{8}$ A metodologia da história oral já está bastante consolidada nas ciências humanas. Nos relatos de experiências muito específicas, procurou-se observar a coerência interna e "contrastar estas imaxes persoais elaboradas a posteriori con outras fontes convencionais” (SOUTELO VÁZQUEZ, 1998, p. 103). No Brasil, é indispensável a referência a Verena Alberti (2005) nas discussões sobre o assunto.

${ }^{9}$ Sobre estudos que abordam o tema dos imigrantes espanhóis que fugiram das perseguições após a derrota dos republicanos, ver Bastani (2006) e Prochnow (2009). ${ }^{10}$ Núñez Seixas (2001, p. 45) reconhece, por um lado, a importância da história oral e histórias de vida na abordagem da "vivencia e experiencia da emigración de retorno por parte dos seus propios protagonistas"; por outro, alerta para problemas metodológicos que residem "en como evita-lo impresionismo descritivo; e, doutra banda, en como medi-lo carácter representativo das mostras orais ou das historias de vida respecto do conxunto dos retornados e emigrados".

${ }^{11}$ Peres (2003, p. 136, 160-165) descreve, com citações de entrevistas e outras fontes, como os carros e as motocicletas encantaram os jovens galegos na década de 1950. ${ }^{12}$ Sobre imigrantes repatriados do Rio de Janeiro, ver Silva (2006, f. 98-104). Este tipo de retorno é diferente do contemporâneo, que se processa com supervisão e apoio do governo espanhol através da Oficina Española del Retorno (CARTA DE ESPAÑA, 2007).

${ }^{13}$ Os nascidos no Brasil tanto podem ser filhos de imigrantes mais antigos quanto brasileiros que estabeleceram enlaces matrimoniais com espanhóis e seus descendentes. Para evitar confusões, esses registros não estão sendo contabilizados.

${ }^{14}$ Assim como os sócios poderiam tanto ser brasileiros como espanhóis, os registros, dependendo de quem os redigia, podiam estar em português ou espanhol. Por exemplo, a profissão "engenheiro" também está registrada como "ingeniero".

${ }^{15}$ Peres (2003, p. 272) também registra o trabalho de cantaria entre galegos em São Paulo.

${ }^{16}$ Snta Comba é também o nome de um município no qual se manifestou o fenômeno de uma tradição de imigração para o Rio de Janeiro, intensivamente estudada por Silva (2006).

17 “A 'etnicidade', para a maioria dos descendentes de imigrantes, é representada com base num ethos do trabalho. Os imigrantes são concebidos por si mesmos como pioneiros e civilizadores - os que transformaram as florestas do Sul do Brasil em 'ilhas' de civilização; ou como aqueles que dignificaram o trabalho num país onde tudo foi deixado nas mãos dos escravos" (SEYFERTH, 1990, p. 87). 
${ }^{18}$ Para relativizar esse fator, através de uma representante do governo espanhol, que supervisionava a aplicação das pensões assistenciais, obtivemos a indicação de alguns pensionistas, isto é, de "españoles residentes en el exterior mayores de 65 años, que carezcan de recursos y vivan en países donde los sistemas públicos de protección social no cubran sus necesidads básicas" (MÁS PENSIONES..., 2007, p. 7). Por outro lado, não privilegiamos imigrantes que estão em posição de destaque na sociedade riograndense.

${ }^{19}$ Provavelmente, no Rio Grande do Sul a porcentagem desses autônomos tenha sido maior que no estado de São Paulo e alocada em ramos mais especializados ver Maciel e Antonacci (1995, p. 183).

${ }^{20}$ A avaliação do sucesso é sempre relativa, mas podemos destacar: ela está no ramo há vinte anos e, como tem bastante demanda, pode delimitar o número de unidades das encomendas de pratos. Para um empreendimento caseiro, trata-se de um bom desempenho.

\section{Referências}

ALBERTI, V. Histórias dentro da História. In: PINSKI, C. B. (Org.). Fontes históricas. São Paulo: Contexto, 2005. p. 155-202.

ALMANAQUE ABRIL 1979. São Paulo: Abril, 1978.

BASTANI, R. F. A imigração espanhola no Rio Grande do Sul através do olhar da mulher. In: PAIVA, S. R. de. (Org.). Mulheres do Rio Grande do Sul: diversidade. Porto Alegre: SFERASRP Editora de Artes, 2006. p. 87-144.

CÁNOVAS, M. D. K. A grande imigração européia para o Brasil e o imigrante espanhol no cenário da cafeicultura paulista: aspectos de uma in(visibilidade). Saeculum: Revista de História, n. 11, p. 115-135, 2004.

CARMEN BARCIA, M. Del. A sociabilidade formal: os centros rexionais españois en Cuba. Estudios Migratorios, n. 7-8, p. 77-94, 1999.

CARTA DE ESPAÑA. Madrid: Ministerio de Trabajo y Asuntos Sociales, Secretaría de Estado de Inmigración y Emigración, n. 627, mayo 2007.

FENTON, S. Etnicidade. Lisboa: Instituto Piaget, 2003.

FERNÁNDEZ VICENTE, M. J. Em busca de la legitimidad perdida. La política de emigración del régimen franquista, 1946-1965. Estudios Migratorios Latinoamericanos, v. 19, n. 56, p. 3-29, 2005. 
GANS, H. J. Symbolic ethnicity: the future of ethnic groups and cultures in America. In: SOLLORS, Werner (Ed.). Theories of ethnicity: a classical reader. New York: New York University Press, 1996. p. 424-459.

GLAZER, N., MOYNIHAN, D. P. (Ed.). Ethnicity, theory and experience. Cambridge, MA: Harvard University Press, 1975.

GONZÁLEZ MARTÍNEZ, E. E. O Brasil como país de destino para os migrantes espanhóis. In: FAUSTO, B. (Org.) Fazer a América: a imigração em massa para a América Latina. 2. ed. São Paulo: Edusp, 2000. p. 239-271.

GUIMARÃES, L. M. P. Breves reflexões sobre o problema da imigração urbana: o caso dos espanhóis no Rio de Janeiro (1880-1914). Acervo. Revista do Arquivo Nacional, Rio de Janeiro, v. 10, n. 2, p. 179-198, jul./dez. 1997.

INSTITUTO BRASILEIRO DE GEOGRAFIA E ESTATÍSTICA. Recenseamento geral do Brasil (1 ${ }^{\circ}$ de setembro de 1940): série regional: parte XX: Rio Grande do Sul: tomo 1: censo demográfico. Rio de Janeiro, 1950. Disponível em http:// biblioteca.ibge.gov.br/visualizacao/monografias/GEBIS\%20-\%20RJ/CD1940/ Censo\%20Demografico\%201940_pt_XX_t1_RS.pdf Acesso em 12 mar. 2009.

. VI Recenseamento geral do Brasil - 1950: Estado do Rio Grande do Sul: censo demográfico: série regional: volume XXVIII: tomo 1. Rio de Janeiro, 1955. Disponível em http://biblioteca.ibge.gov.br/visualizacao/monografias/ GEBIS\%20-\%20RJ/CD1950/CD_1950_XXVIII_t1_RS.pdf Acesso em 12 mar. 2009.

- Censo demográfico de 1960: Rio Grande do Sul: VII recenseamento geral do Brasil: série regional: volume I: tomo XVI:. Rio de Janeiro, 1967. Disponível em http://biblioteca.ibge.gov.br/visualizacao/monografias/GEBIS\%20-\%20RJ/ CD1960/CD_1960_RS.pdf Acesso em 12 mar. 2009.

KLEIN, H. S. A imigração espanhola no Brasil. São Paulo: Editora Sumaré: Fapesp, 1994.

. Migração internacional na história das Américas. In: FAUSTO, B. (Org.) Faz̧er a América: a imigração em massa para a América Latina. 2. ed. São Paulo: Edusp, 2000. p. 13-31.

KRELING, W. F. História da Casa de Espanha de Porto Alegre. Dissertação (Mestrado em História) - Faculdade de Filosofia e Ciências Humanas, Pontifícia Universidade Católica do Rio Grande do Sul, Porto Alegre, 1979.

LA REGIÓN INTERNACIONAL. Madrid, 1966. [Quinzenal].

MACIEL, L. A., ANTONACCI, M. A. M. Espanhóis em São Paulo: modos de vida e experiências de associação. Projeto História, n. 12, p. 173-192, 1995. 


\section{Galegos no sul do Brasil:...}

MANNHEIM, K. Diagnóstico de nosso tempo. 4. ed. Zahar: Rio de Janeiro, 1980.

MÁS PENSIONES asistenciales. Carta de España, n. 675, p. 6-11, marzo 2007.

MUNIZ, K. C. P. Os filhos de Santiago em terra carioca: construção da identidade espanhola. Rio de Janeiro: UFRJ/IFCS, 1996.

NÚÑEZ SEIXAS, X. M. Emigración transoceánica de retorno e cambio social na Península Ibérica: algunhas observacións teóricas en perspectiva comparada. Estudios Migratorios, n. 11-12, p. 13-52, 2001.

OLIVEIRA, M. C. V. M. de. CDE, um espaço da Espanha no coração de São Paulo: centro de cultura e resistência ao franquismo, 1957-1975. Dissertação (Mestrado em História) - Faculdade de Ciências Sociais, Pontifícia Universidade Católica de São Paulo, São Paulo, 1997.

PERES, E. P. A inexistência da terra firme: a imigração galega em São Paulo, 19461964. São Paulo: Editora da Universidade de São Paulo: Fapesp: Imprensa Oficial do Estado, 2003.

POUTIGNAT, P., STREIFF-FENART, J. Teorias da etnicidade. São Paulo: Editora da Unesp, 1998.

PROCHNOW, L. N. Memórias, narrativas e história: a imigração espanhola recente em Porto Alegre. Dissertação (Mestrado em História) - Faculdade de Filosofia e Ciências Sociais, Pontifícia Universidade Católica do Rio Grande do Sul, Porto Alegre, 2009.

SAYAD, A. A imigração. São Paulo: Editora da Universidade de São Paulo, 1998.

SEYFERTH, G. Imigração e cultura no Brasil. Brasília: Editora da UnB, 1990.

As identidades dos imigrantes e o melting pot nacional. Horizontes Antropológicos, Porto Alegre, ano 6, n. 14, p. 143-176, 2000.

SILVA, É. S. Galegos no Rio de Janeiro (1850-1970). Tese (Doutorado) - Facultade de Geografía e Historia, Universidade de Santiago de Compostela, Santiago de Compostela, 2006.

SIXIREI PAREDES, C. Galeguidade e cultura no exterior. Xunta de Galicia, [s.d.].

SOUTELO VÁZQUEZ, R. Memoria oral e identidade étnica da inmigración española a latinoamérica no século XX: os galegos en Brasil, 1880-1970. Estudios Migratorios, n. 6, p. 97-124, 1998.

VAZQUEZ GONZALEZ, A. El uso de fuentes personales para o estúdio de la emigracion de Galicia: estado presente y perspectivas. Estudios Migratorios Latinoamericanos, v. 11, n. 33, p. 313-355, 1996.

WALLERSTEIN, I. O sistema mundial moderno. Porto: Afrontamento, 1990. v. 1. 
ZUBILLAGA, C. Notas para una tipología de los liderazgos en la inmigración española en Uruguay, 1870-1960. Estudios Migratorios Latinoamericanos, v. 15, n. 44, p. $147-163,2000$.

\section{Fontes orais}

Entrevistas com imigrantes espanhóis atualmente residentes na Região Metropolitana de Porto Alegre.

Recebido em: 15/04/2010 Aprovado em: 21/05/2010 